\title{
Enhancing Older People's Participation in the Electoral Process in Liberia
}

\author{
Nina M Silverstein ${ }^{1 *}$ and Sam Togba Slewion ${ }^{2}$ \\ ${ }^{1}$ Social Work Department, United Methodist University, Liberia \\ ${ }^{2}$ Department of Gerontology, University of Massachusetts, USA
}

*Corresponding author: Nina M Silverstein, Social Work Department, United Methodist University, Liberia

\begin{abstract}
Social policy development in Liberia falls short in representing the voices of the country's 180,000 people aged 65 or over in determining policies aimed at enhancing the quality of life of its older citizens. This subtle exclusion of older people appears in the context of the lack of legislation and a national social protection policy for older people's rights, including housing, health care and transportation. Many older Liberians do not register to vote and of those who register, they may not actually cast their ballots. This pilot research sought to explore the voting trend of older people in Liberia's electoral process with the goal of providing insights toward understanding the barriers that are undermining the participation of older people.

Data were reviewed from previous elections, specifically voter registration rolls for 2005, 2011, 2014 and 2017, and of actual voters in the 2005, 2011 and 2017 presidential and general elections. In addition, five focus groups and a survey involving almost 5,000 older people, including women and men in three counties, Montserrado, Grand Bassa and Margibi Counties was conducted. The survey response rate was 40\% (2000). Preliminary findings suggest that the empowerment of older people in Liberia through increased participation in the electoral process will lead to not only improving the democratic space for everyone, including older people, but also the capacities of relevant actors to effectively serve the older adult community and address the critical concerns of that population.
\end{abstract}

Keywords: Voter participation; older adults; barriers; Liberia

\section{Introduction}

While developed countries, continue to make progress in caring for an aging population, developing countries such as Liberia, face a lack of a social protection policy. In Liberia, the welfare of over 180,000 people aged 65 or older seems to be an after-thought instead of an inclusive segment of any social policy aimed at enhancing the quality of life of older citizens of the country. This subtle exclusion of older people is manifesting in Liberia in the context of the lack of legislation and a national social protection policy for older people's rights and improvement of their quality of life, including housing, health care and transportation.

The continued neglect of older people in Liberia was highlighted significantly during the recent deadly Ebola outbreak in the country, which claimed the lives of over 4,800 persons and over 10,000 Ebola-infected persons [1]. There were specific responses in the National Ebola Response Policy for those the government considered the most vulnerable groups, specifically women and children, ironically leaving out older people, the most "vulnerable of the vulnerable" social groups [2].

This action of the Liberian government prompted scholar activists like Professor Slewion (author) to engage the Liberian government constructively to ensure that older people were visible during the peak of the Ebola epidemic in Liberia and included in the national response policy. This action of activism and constructive engagement led to two important outcomes:

a) Older people became visible during the Ebola crisis and received relief supplies, preventive materials and health educational materials distributed by the Liberian government and international partners allowing them to survive the crisis

b) The formation of a national movement for older people rights in Liberia called the Coalition of Caregivers and Advocates for the Elderly in Liberia (COCAEL) in August, 2014 [3]. 
While the formation of COCAEL is laudable, there is still a lot to be done to improve the quality of life of older people in Liberia as older Liberians continue to face marginalization and neglect during elections. Several factors contribute to that marginalization and neglect, including failure to implement electoral laws relative to preferences for older people, lack of awareness of the electoral laws by older people, and inaccessible voting centers and precincts [4]. surmised that over their lifetimes, citizens tend to habituate voting and comply with a growing subjective norm of voting. Furthermore, the average voting participation of older people is influenced by their longer duration of residence, the lack of a mobilizing partner, worse physical health and less education, although life experiences replaces the function of formal education over a lifetime.

\section{Conceptual Framework}

The Senior Power Model starts with the fact that older people constitute a numerical significant portion of the electorate and then assumes that their political behaviour is guided by their selfinterest and that most older people perceive their interest to be the same [5]. These assumptions have their roots in a view of voting behavior that emerged in neoclassical economics and Satisfactory Decision Theory, which predicts that each voter's decision among candidates is rationally calculated on the basis of complete and accurate information to optimize his or her self-interest [6]. Realizing that civil action is always an effective tool for societal change [7], it has become imperative that strategic plans be devised to increase the political capital of older people in Liberia.

Hence, the primary objective of the pilot study was to identify the deficiencies and gaps in the electoral system and policies and service delivery to the older population in Liberia and address these deficiencies and gaps to improve policy outcomes and enhance services to older citizens. A secondary objective was to strengthen gerontology studies in Liberia by increasing the research skills of social work students through engaging them directly in applied research on issues impacting older adults.

\section{Methods}

A mixed-method approach was utilized including document review, focus groups, and in-person survey administration. The research began with a review of elections data, including data reviewed from previous elections, specifically voter registration rolls for 2005, 2011, 2014 and 2017, and data of actual voters in the 2005, 2011 and 2017 presidential and general elections; five focus groups with older people were conducted and in-person surveys administered across counties in geographically diverse communities. The communities were selected because they are a macrocosm of the greater Liberian society in terms of the ethnic and religious diversity. For example, Kakata city in Margibi County and Buchanan city in Grand Bassa County are bustling business cities that attract lot of people on a daily basis.

Policy reports were reviewed from HelpAge International documenting the socio economic condition older people face due to lack of a universal protection instrument such a UN Convention for older people, WHO Report on the Ebola epidemic in 2015 in Liberia, the African Social Work Journal highlighting the challenges of older people during the Ebola outbreak in three West African countries, including Liberia and the dismal socio-economic conditions endured (HelpAge International newsletter, 2017; [3]); and statistical data about the population of older people in Liberia (LISGIS, 2008). The National Elections Commission (NEC) archive was available for review and includes a good database of election activities based on support and technical assistance provided to the Commission by the United Nations Development Project (UNDP) and International Federal Electoral System of the United States of America.

Five focus groups of 15-20 persons were conducted in three counties, including Montserrado, Margibi and Grand Bassa in May through October 2017. Two focus groups were held in Montserrado County, which is the most populated county of the 15 counties in Liberia. Two in Margibi County conducted in Kakata and Unification Town in in September 2017 [8], and a final group held in Buchanan, Grand Bassa County in October, 2017. The questions that guided the focus groups are provided in Appendix A.

The individuals who participated in the focus groups were purposively selected based on their interest and commitment to aging issues. The survey sample included males and females of different ages, ethnic backgrounds and social economic status as reflected in Table 1.

Table 1: Gender and Religion by County $(n=2000)$.

\begin{tabular}{|c|c|c|c|}
\hline Gender & Montserrado & Margibi & Bassa \\
\hline Male & 700 & 200 & 425 \\
\hline Female & 300 & 175 & 200 \\
\hline \multicolumn{4}{|c|}{ Religion } \\
\hline Christian & 600 & 175 & 400 \\
\hline Islamic & 300 & 125 & 175 \\
\hline Others & 100 & 75 & 50 \\
\hline
\end{tabular}

The survey was administered in-person among targeted groups of older people in the areas in which the focus groups were conducted. Some of the participants filled out the survey by themselves and returned the completed survey to the staff, while others, who could not read and write, were interviewed in person in a private area to ensure that privacy and confidentiality were not compromised. In addition to the staff of the CECAFE, some members of the Coalition of Caregivers and Advocates for the Elderly in Liberia (COCAEL) and five undergraduate students of the Social Work Department of UMU assisted in the research.

The research protocol was approved by the University of Massachusetts Boston Institutional Research Board, the home institution of the co-investigator. The survey design included a brief description of the study, confidentiality statement, demographic questions, and sets of both closed and open-ended questions. There were 24 questions to determine the participant involvement with the electoral process in Liberia either as a registered voter or nonregistered voter [9-12], participant understanding of the electoral laws and process in the context of age discrimination, location of registration centers and voting precincts, and accessibility of registration centers and voting precincts. Five thousand older 
people, including women and men in three counties, Montserrado Grand Bassa, and Margibi counties were surveyed yielding a $40 \%$ (2000) response rate. These counties which are several miles apart and outside of the capital city, Monrovia, including Margibi and Grand Bassa Counties, are usually accessible throughout the year, including the rainy season, compared to the other counties. Inaccessible road conditions (most roads had potholes and were cut off to vehicle traffic) during the rainy season limited the ability of the research team to reach other areas with a high concentration of older people.

\section{Sample Description}

The survey sample size of 2,000 persons was comprised of males and females age 60 years old and above. There were no other inclusion criteria beyond age and the resulting sample represented diverse backgrounds of participants reflecting the broad profile of older people in Liberia. Christianity is the dominant religious group in the country and there is an assumption that more Christian older people are facing challenges. The data presented in this study illustrate that electoral challenges among older people are being experienced by other religious groups as well Table 1 .

\section{Results}

The document review of the NEC data indicates Table 2 that there is a consistent increase in registration of older voters incrementally in the last three general and presidential elections. NEC data were not available on the number of actual voters among older adults in these elections. The elections data also illustrate that while there is a slight increase in the registration of older male adults in the last three elections, the number of older female adults has peaked without any increase or decrease in the number of registered older female voters.

Table 2: Summary of Voter Registration Statistics, 2005-2017.

\begin{tabular}{|c|c|c|c|c|c|c|}
\hline Year & Gender & Age & Registered Voters & Percentage & Average Age & Total Voters \\
\hline \multirow{12}{*}{2005} & & & & & 35 & $1,352,730$ \\
\hline & Female & & 676,390 & $50 \%$ & & \\
\hline & Male & & 676,340 & $50 \%$ & & \\
\hline & Total population age $58+$ & $68+$ & & $5 \%$ & & \\
\hline & & $63-67$ & & $2 \%$ & & \\
\hline & & $58-62$ & & $2 \%$ & & \\
\hline & \multirow{3}{*}{ Female } & $68+$ & & $2.60 \%$ & & \\
\hline & & $63-67$ & & $1.20 \%$ & & \\
\hline & & $58-62$ & & $1.80 \%$ & & \\
\hline & \multirow{3}{*}{ Male } & $68+$ & & $2.4 \% \%$ & & \\
\hline & & $63-67$ & & $1.20 \%$ & & \\
\hline & & $58-62$ & & $1.40 \%$ & & \\
\hline \multirow{12}{*}{2011} & & & & & 35 & $1,798,930$ \\
\hline & Female & & 878,482 & $49 \%$ & & \\
\hline & Male & & 920,448 & $51 \%$ & & \\
\hline & Total population age $58+$ & $68+$ & & $2 \%$ & & \\
\hline & & $63-67$ & & $2 \%$ & & \\
\hline & & $58-62$ & & $3 \%$ & & \\
\hline & \multirow{3}{*}{ Female } & $68+$ & & $1.10 \%$ & & \\
\hline & & $63-67$ & & $1.10 \%$ & & \\
\hline & & $58-62$ & & $1.60 \%$ & & \\
\hline & \multirow{3}{*}{ Male } & $68+$ & & $1.00 \%$ & & \\
\hline & & $63-67$ & & $1.00 \%$ & & \\
\hline & & $58-62$ & & $1.50 \%$ & & \\
\hline \multirow{9}{*}{2017} & & & & & 35 & $2,183,683$ \\
\hline & Female & & $1,062,733$ & $49 \%$ & & \\
\hline & Male & & $1,120,950$ & $51 \%$ & & \\
\hline & Total population age $58+$ & $68+$ & & $4 \%$ & & \\
\hline & & $63-67$ & & $2 \%$ & & \\
\hline & & $58-62$ & & $3 \%$ & & \\
\hline & \multirow{3}{*}{ Male } & $68+$ & & $1.80 \%$ & & \\
\hline & & $63-67$ & & $1.00 \%$ & & \\
\hline & & $58-62$ & & 1.5 & & \\
\hline
\end{tabular}

Citation: Nina M S, Sam Togba S. Enhancing Older People's Participation in the Electoral Process in Liberia. Res \& Rev Health Care Open Acc 


\begin{tabular}{|l|c|c|c|c|c|}
\hline \multirow{4}{*}{ Female } & $68+$ & $2.50 \%$ & & \\
\cline { 3 - 5 } & & $63-67$ & & $1.00 \%$ & \\
\cline { 3 - 5 } & & $58-62$ & & 1.6 & \\
\hline
\end{tabular}

\section{Barriers and Challenges Revealed}

The survey findings suggest that the empowerment of older people in Liberia through increased participation in the electoral process and creation of a partnership will lead to not only devising strategies to improve the democratic space for everyone, including older people, but also the capacities of relevant actors to effectively serve older adults and address the critical concerns of that population. The major themes that emerged from the survey analysis were awareness, physically accessibility, language accessibility, and attitude toward voting.

a) Awareness: While most (80\%) of the respondents knew the location of their registration centers and voting precincts, they were less knowledgeable of the electoral laws relative to knowing their rights, privileges, and treatment to expect at voting and registration centers with $90 \%$ reporting the lack of familiarity with the laws.

b) Physical accessibility: About $90 \%$ of the respondents did not feel that their registration centers and voting precincts were accessible to them (i.e. no ramps for wheelchair, not agefriendly, no preference for older people to move ahead of long lines to avoid standing too long).

c) Language accessibility: About $90 \%$ of the respondents did not know and understand the elections laws and procedures for registration and voting and attributed the situation to the fact that most of the public awareness campaign about elections laws and voting is done in English and they find it difficult to clearly understand the content and intention of the message of the campaign. This situation tended to affect a majority of the respondents, with about $90 \%$ reporting that they felt left out of the public awareness campaign because of language barriers. For many of the older adults, the languages preferred are the languages of the three majority ethnic groups such as Lorma, Kissi, Kpelle, Gio or Manor.

d) Attitude toward voting: About $60 \%$ of the registered older voters surveyed indicated that do not vote due to the harsh conditions they face at the voting precincts, including standing too long in lines, lack of accessible voting precincts and unfriendly staff. Most all (95\%) of the respondents thought they should have a separate voting line to speed up their voting process to avoid standing too long in line due to the frail conditions experienced by many of them.

Most of these sentiments expressed above were also reflected in the focus groups meetings. For example, an older female told the group: "It will be good for the election people to put the election announcements in our dialect so we can know what they [are] talking [about]". Another older man explained: "the election people can be speaking big English and it hard for us to know what they [are] saying". Another statement repeated by several focus group participants when asked for the reasons why older people may not vote was, "the way the people [at the polls] treat us when we go to vote, that's why most old people don't like to vote during voting time."

\section{Discussion}

This pilot study was conducted to understand the barriers and challenges older people in Liberia face during the electoral process in Liberia. The document review of NEC data revealed that while there has been an increase in the voter registration of older Liberians, it does not reflect an increase in voting behavior, particularly among older women. The reasons for these outcomes are not clear, but based on the results of the survey and the focus groups meetings, contributing factors likely include a lack of intentional strategy by the NEC, including age-specific public awareness campaign messages, sensitivity training among its staff and age-friendly voter registration centers and precincts, to increase the participation of older adults in the electoral process in the country.

\section{Limitations}

In addition to the concerns above, another limitation was the inaccessibility of the research team to some counties with larger voting populations, including Nimba and Lofa Counties, due to the road conditions based on the weather at the time the survey and focus groups meetings were conducted. Future research should make efforts to expand data collection to a broader representation of counties.

\section{Recommendations}

A number of recommendations emerged from this research.

(1) That the investigators work with various stakeholders, including the National Elections Commission (NEC) of Liberia and older people themselves, to design strategies to increase the political and social capital that could be leveraged to improve the socio-economic conditions of older people.

(2) That the NEC of Liberia intentionally design mechanisms, including making voting precinct accessible to older people and creating separate voting lines to mitigate the disenfranchisement of older people and increase their participation in the electoral process.

(3) That the NEC includes cultural sensitivity training into its training for poll staff to improve their sensitivity to older voters during elections.

(4) That the NEC educate older people about the electoral laws of Liberia through specific older voters' education and awareness programs, using culturally sensitive activities, including radio dramas and various local vernaculars/languages.

(5) That older people and advocates in Liberia join international campaigns (i.e. Global Alliance for the Rights for Older People-GAROP through the Open-Ended-Working -Group) to 
advocate for the enactment of a UN Convention for older people to mandate governments to create programs and infrastructures to lift older people out of poverty, abuse and isolation.

(6) That the older people and advocates in Liberia engage with policy makers in Liberia to ratify the African Protocol on the Rights of Older People in Africa to mandate governments to create programs and infrastructures to lift older people out of poverty, abuse and isolation.

(7) That advocacy groups for older people strive to create an environment for generational engagement to include young people in their advocacy campaign for the rights of and improved services for older people.

\section{Conclusion}

This study provided insight into the barriers and challenges facing older people's participation in the electoral process in Liberia. It also enabled the researchers to engage with older people from diverse backgrounds and understand from them the approaches to be used to address these challenges. In addition, the study provided an opportunity for social work students to engage directly with older people and helped to create an environment for intergenerational dialogue on the socio-economic issues confronting older people. This engagement enabled students to come face to face with the realities of life that older people live in the country on a daily basis. Most of the students expressed that they were not aware that older people were not only living in poverty, but also were disenfranchised due to harsh conditions they face at voting precincts throughout the country. They observed that older women were a majority of the victims.

Some students seemed to be motivated to join advocacy campaigns and groups to advocate for improvement in the quality of life of older people in Liberia. "I was not aware that most of these older people did not vote because of these problems," one female student said. "Our government needs to do more for our old people," quipped a male student. It was also observed that the lack of political capital seems to be a contributing factor for the high level of poverty, abuse, discrimination and isolation being experienced by older people in Liberia. Despite all of these different social issues, the emerging themes consistent from the focus groups and survey were the high level of poverty, a lack of interest and trust in the electoral process and marginalization of older people in the electoral process in Liberia due to inaccessible voting precincts, and insensitivity of polling staff.

An important update to note is that shortly after data collection concluded for this study, during the presidential and general elections held in October 2017 and the run-off held in December 2017, there seemed to be a slight improvement in the treatment of older people in some voting areas.It was reported that some older people were allowed to move ahead of the long queues either due to the courtesy of other voters or at the urging of poll workers. Despite the slight improvement, there is still a lot to be done to improve the quality of electoral participation of older people in Liberia.

It is expected that this study will stimulate opportunities for other ongoing activities, including strengthening the advocacy efforts among advocates for the elderly in Liberia, using the data and findings obtained to engage stakeholders to develop a national policy for aging and make policy changes. These policy changes can include election policy and mechanisms to enhance the participation of older people in the electoral politics in the country and the social protection for the 180,000 older Liberians.

Moreover, the findings will help to inform policy and increase the political capital of older people to advocate for conditions to improve their quality of life. The findings suggest that the empowerment of older people in Liberia through increased participation in the electoral process will lead to not only devising strategies to improve the democratic space for everyone, including older people, but also the capacities of relevant actors to effectively serve the elderly community and address the critical concerns of that population.

\section{Acknowledgment}

Preliminary findings of this research were presented at the Association of Gerontology in Higher Education (AGHE) Education and Leadership Conference, The Global Business of Aging (March, 2018; Atlanta, Georgia). This project was supported, in part, from a grant through the International Research/ Education/ Learning Initiative Seed Grants Program, Office of Global Programs, University of Massachusetts Boston.

\section{Declaration of Interest Statement}

In accordance with Taylor \& Francis policy and our ethical obligation as researchers, we are reporting that we do not have any financial and/or business interests that may be affected by the research reported in the enclosed paper.

\section{Appendix A. Focus Group Questions}

a. Do many older people register to vote, if yes, why? If no, why?

b. How do you think older people can make the Elections Commission make voting easier for them?

c. What do you think are the reasons more older people do not go to the polls to vote?

d. In what ways do older people think their votes can make their condition better for them?

e. In what ways do older people think their votes are important?

f. What can older people do to get more older people to vote?

g. Do older women face the same problem at the polls like older men? If no, why? If yes, why?

h. Do older men face the same problem at the polls like older women? If no, why? If yes, Why?

i. What does the National Elections Commission (NEC) mean that anyone that is "mentally incompetent" cannot be allowed to vote? 
j. In your opinion, should all older people be allowed to vote? If yes, why? If no, why?

\section{References}

1. WHO (2014) Ebola Response Roadmap Situation Report.

2. Republic of Liberia (2014) National Ebola response strategy.

3. Slewion S (2015) Brief communication: Giving older people a voice in Liberia, west Africa. African Journal of Social Work 5(1): 131-137.

4. Binstock R (2000) Older people and voting participation: Past and future. Gerontologist 40(1): 18-31.

5. Binstock R (2005) Old-age policies, politics, and ageism. Generations 29(3): 73-78.

6. Svein olav Daatland (2001) The Politics of Old Age in Europe. 230 pp. Buckingham. Ageing and society 21(3): 357-368.
7. Lovey RD (1997) The Civil Rights Act of 1964: The passage of the law that ended racial segregation. State University of the New York Press, USA.

8. The Global human capital report 2017. World economic forum.

9. (2008) population and Housing census of Liberia. Liberia Institute of Statistics \& Geo-Information Service.

10. Liberia National Elections Commission (2019) Elections results-2005, 2011 and 2017.

11. Palfrey TR, Poole KTC (1987) The relationship between information, ideology and voting behavior. American Journal of Political Science 31: 511-530.

12. Small B (2017) International HelpAge programme restores livelihoods and builds community cohesion in post-Ebola Sierra Leone. HelpAge International.

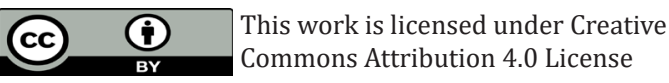

To Submit Your Article Click Here: Submit Article

DOI: $10.32474 /$ RRHOAJ.2019.04.000181

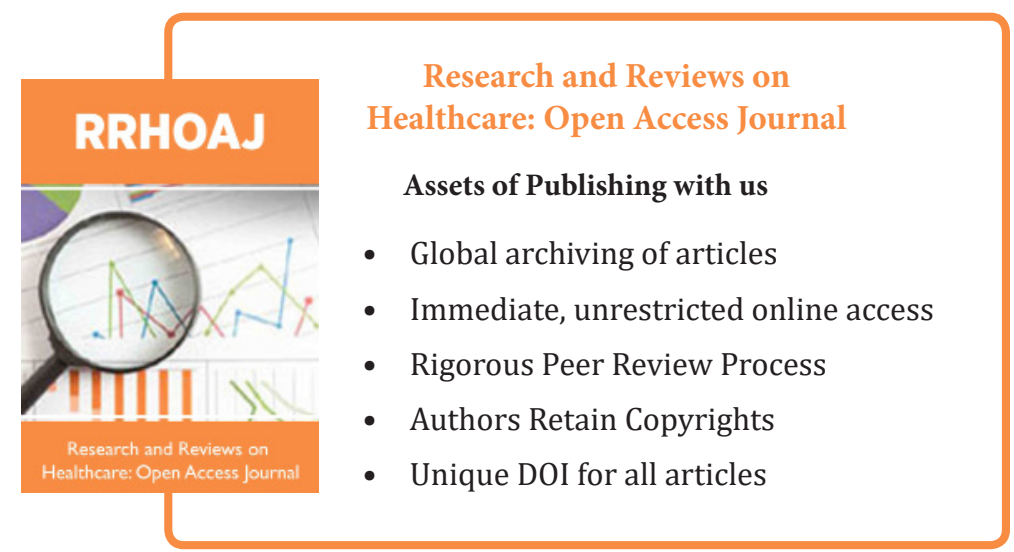

